\title{
List of abbreviations and Irish terms
}

$\begin{array}{ll}\text { AkiDwa } & \text { Akina Dada wa Africa (African Women's Organisation) } \\ \text { ASC } & \text { Africa Solidarity Centre / Africa Centre } \\ \text { CBP } & \text { Common Basic Principles for Immigrant Integration in the European } \\ & \text { Union } \\ \text { D15 } & \text { Dublin } 15 \\ \text { Dáil } & \text { Parliament, lower house } \\ \text { DEIS } & \text { Delivering Equality of Opportunity in Schools } \\ \text { DICP } & \text { Dublin Inner City Partnership } \\ \text { DJELR } & \text { Department of Justice, Equality and Law Reform } \\ \text { DWS } & \text { The Developmental Welfare State } \\ \text { ED } & \text { electoral district } \\ \text { ELS } & \text { English Language Support } \\ \text { ESRI } & \text { Economic and Social Research Institute } \\ \text { EU-10 } & \text { The new 2004 European Union member states } \\ \text { FAS } & \text { Foras Áiseanna Saothair (Irish state employment training agency) } \\ \text { Gardai Síochána } & \text { Irish Police } \\ \text { HRC } & \text { Habitual Residence Condition } \\ \text { ICI } & \text { Immigrant Council of Ireland } \\ \text { IoD } & \text { Index of Dissimilarity } \\ \text { MRCI } & \text { Migrants Rights Centre Ireland } \\ \text { NASC } & \text { Cork immigrant support group } \\ \text { NESC } & \text { National Economic and Social Council } \\ \text { NCCRI } & \text { National Consultative Committee on Racism and Interculturalism } \\ \text { Oireachtas } & \text { Parliament, both houses } \\ \text { PPS } & \text { Personal Public Service number } \\ \text { Taoiseach } & \text { Prime Minister } \\ \text { VRC } & \text { Vincentian Refugee Centre } \\ \text { WBCFN } & \text { well-being of children, families and neighbourhoods } \\ \end{array}$


Bryan Fanning - 9781847794192

Downloaded from manchesterhive.com at $04 / 26 / 2023$ 08:22:52AM via free access 